\title{
Utilization of chlorophyll content index (CCI) to infer yellow rust severity in wheat (Triticum aestivum $\mathrm{L}$. .)
}

\author{
C. N. Mishra*, Satish Kumar, Vikas Gupta, Vinod Tiwari and Indu Sharma \\ Directorate of Wheat Research, Karnal- 132001 (Haryana), INDIA \\ *Corresponding author. E-mail: mishracn1980@gmail.com
}

Received: September 22, 2014; Revised received: February 9, 2015; Accepted: February 16, 2015

\begin{abstract}
Stripe rust caused by Puccinia striformis Westend. f. sp. tritici Eriks. (Pst) is a major constraint to wheat production in Northern India. In this study, 616 indigenous germplasm (IC) accessions of wheat were screened under field conditions against mixture of Pst isolates at DWR Karnal during 2012-13 crop season. Out of 616 accessions, 197 accessions were observed to be resistant (R), 115 moderately resistant (MR) to moderately susceptible (MS) and 304 as susceptible (S) against yellow rust. On the basis of days to heading, the accessions were grouped into four classes (early, medium early, medium late and late). Chlorophyll content index (CCl) recorded in flag leaf showed significant differences between resistant and susceptible lines in each classified group at $5 \%$ level of significance. The difference for $\mathrm{CCl}$ between resistant and moderately resistant plants was negligible, however in comparison with resistant plants, susceptible plants showed loss of $35-39 \%$ of chlorophyll. There was negative correlation (a correlation coefficient of -0.60 ) between chlorophyll content and disease severity due to stripe rust in susceptible accessions.
\end{abstract}

Keywords: Chlorophyll reduction, Disease severity, Stripe rust, Wheat

\section{INTRODUCTION}

Wheat production is an important component of food security all over world. Stripe rust disease of wheat causes yield losses every year. Worldwide, 43 million ha $(46 \%)$ and in India about 9.4 million ha $(>35 \%)$ area under wheat cultivation is prone to stripe rust (Singh et al., 2004). The changes in climatic conditions have led to frequent incidences of this killer disease on wheat crop in northern and north-western parts of India. The north western plains zone of India comprising (Punjab, Haryana, Delhi, Rajasthan (except Kota and Udaipur divisions) and Western Uttar Pradesh (except Jhansi division), parts of J\&K (Jammu \& Kathua districts) and parts of Himachal Pradesh (Una district and Paonta valley) and Uttarakhand (Tarai region) is the most productive zone and is important with respect to food security of the nation (Anonymous, 2014). The stripe rust incidence in these zones prevents the harvest of the full potential of cultivars. Stripe rust propagates in cool and moist environments and can infect wheat crop in the early growth stages leading to yield losses as high as $50 \%$ (Roelfs et al., 1992). Although a number of rust resistance genes have been identified in wheat (McIntosh et al., 2010), a major problem has been their short-lived effectiveness due to fast emergence of virulent races of the pathogen that are capable of overcoming the resistance. However, at least four designated resistance genes, Lr34/Yr18, Lr46/Yr29, Sr2/Yr30, and Lr67/Yr46, have conferred partial but durable resistance for a long period of time (Herrera-Foessel et al., 2011;
Singh et al., 2011).

Plant infected with viruses, fungi or bacteria usually exhibit reduced photosynthetic rate (Goodman et al., 1986). Like other diseases, rusts in wheat causes significant abnormalities in form and functions associated with photosynthesis thereby reducing the chlorophyll content. Germplasm acts as a reservoir for the variability for biotic and abiotic stresses. Screening of germplasm should be a regular activity for identifying resistance sources to the present virulent races. Assessment of genetic variability within crop accessions has important implications in resistance breeding and conservation of genetic resources. The objective of the study was to compare the chlorophyll content index among resistant, moderately resistant-susceptible and susceptible plants due to stripe rust in flag leaf of wheat.

\section{MATERIALS AND METHODS}

The plant material comprised 616 indigenous wheat germplasm collections received from NBPG (National Bureau of Plant Genetic Resources) New Delhi. Field experiments were conducted on sandy clay loam with pH 7.9 (1:2.5, soil: water) at new farm of directorate of wheat research (DWR), Karnal $\left(29^{\circ} 43^{\prime} \mathrm{N}, 76^{\circ} 58^{\prime} \mathrm{E}\right.$ and $245 \mathrm{M}$ AMSL). The climate of the experimental site is sub-tropical with mean maximum temperature ranging between $34-39^{\circ} \mathrm{C}$ in summer and mean minimum temperature ranging between $6-7^{0} \mathrm{C}$ in winter.

All the recommended package of practices for raising a good wheat crop was followed. The material was 
timely sown in row length of $1.50 \mathrm{~m}$ with spacing of $20 \mathrm{~cm}$ with border rows of a susceptible infector. Plants were artificially inoculated by urediospore suspension of most virulent and prevalent races (78S84 and 46S119) of Pst obtained from DWR-RS, Flowerdale, Shimla, through mist sprayers (1g urediospores per $\mathrm{ml}$ of distilled water i.e. about 30,000 spores $\mathrm{ml}^{-1}$ with between 20 as emulsifier) twice at the boot stage.

Rust severity on germplasm lines was scored in the field using modified Cobb's Scale (Peterson et al., 1948) and host response to infection, as described in Roelfs et al., (1992); where, 'R' = resistant or miniature uredinia surrounded by necrosis and chlorosis, 'MR' = moderately resistant or small uredinia surrounded with chlorosis or necrosis, 'MS' = moderately susceptible or moderate-sized uredinia without chlorosis or necrosis, and ' $\mathrm{S}$ ' = susceptible or large uredinia without chlorosis and necrosis. The chlorophyll content index (CCI) of flag leaf was measured from the middle part of the leaf by OPTI-SCIENCES CCM 200 plus chlorophyll meter. The CCM 200 uses calibrated light emitting diodes and receptors to calculate the chlorophyll content index (CCI) which is the ratio of percent transmission at 931 and $653 \mathrm{~nm}$ through a leaf sample (Biber, 2007). Heading date was recorded when the head (spike) had emerged from flag leaf on $50 \%$ of the wheat plants in a row. On the basis of days to $50 \%$ heading the wheat germplasm lines were classified into four groups' viz., early, medium-early, medium late and late and CCI was each group was studied with respect to response to infection within the group. Statistical analysis for $\mathrm{t}$ test, correlation and regression was done following Gomez and Gomez (1984).

\section{RESULTS AND DISCUSSION}

Stripe rust response in studied material varied from free to highly susceptible rust response (100S). Out of six hundred sixteen germplasm lines screened, 197 showed resistant (R) type response, 115 showed moderately resistant (MR) to moderately susceptible (MS) response and 304 accessions showed susceptible (S) response to stripe rust. To avoid the effect of senescence on chlorophyll content measurement, these germplasm lines were classified into four groups viz., early, medium-early, medium late and late on the basis of days to $50 \%$ heading (Table 1). The early group had 75 accessions with mean value of 82 days to heading. The medium-early (93 days) and medium late (102 days) group had 186 and 298 accessions, respectively. There were 57 lines in late group with an average of 108 days to $50 \%$ heading.

Data presented in table 1 revealed that in the first group the average chlorophyll content index (CCI) was 16.60 with the range varying from 2.3 to 30.26 .67 per cent of accessions of the group were found to be resistant to yellow rust, whereas 25.33 per cent of accessions were moderately resistant to moderately susceptible. 36 accessions (48\%) showed susceptible response to yellow rust. The CCI of resistant, moderately resistant -moderately susceptible and susceptible accessions was

Table 1. Classification of germplasm accessions on the basis of days to heading and yellow rust reaction in relation with chlorophyll content.

\begin{tabular}{lccccc}
\hline Group & $\begin{array}{c}\text { First group } \\
\text { (Early) }\end{array}$ & $\begin{array}{c}\text { Second group } \\
\text { (Medium Early) }\end{array}$ & $\begin{array}{c}\text { Third group } \\
\text { (Medium late) }\end{array}$ & $\begin{array}{c}\text { Fourth group } \\
\text { (Late) }\end{array}$ & Total \\
\hline Days to flowering & 82 & 93 & 102 & 108 & \\
& $(66-86)$ & $(87-96)$ & $(97-106)$ & $(107-114)$ & 616 \\
Number of & 75 & 186 & 298 & 57 & 197 \\
accessions & 20 & 59 & 97 & 21 & 115 \\
No. of resistant & $(26.67 \%)$ & $(31.72 \%)$ & $(32.56 \%)$ & $(36.84 \%)$ & 9 \\
accessions & 19 & 34 & 53 & $(47.37 \%)$ & 304 \\
No. of MR-MS & $(25.33 \%)$ & $(18.28 \%)$ & $(17.80 \%)$ & 148 & 27 \\
accessions & 36 & 93 & $(49.70 \%)$ & $(15.79 \%)$ & 16 \\
No. of Susceptible & $(48.00 \%)$ & $(50.00 \%)$ & 17 & $(4-34.9)$ & \\
accessions & 16.60 & 18.3 & $(2-31.9)$ & 19.51 & \\
Avg. Chlorophyll & $(2.3-30)$ & $(2.5-34.5)$ & 20.95 & 19.48 & \\
content (range) $\mu \mathrm{g}$ & & 22.37 & 20.48 & 11.78 & \\
cm-2 & 20.07 & 22.24 & 13.21 & 39.62 & \\
CCI-R* & 20.17 & 14.34 & 36.95 & \\
CCI-MR-MS & 12.84 & 35.90 & & & \\
CCI-S & & & & & \\
\% Reduction in CC & 36.02 & & & & \\
of S over R lines & & &
\end{tabular}

${ }^{*} \mathrm{CCI}-\mathrm{R}=\mathrm{Chlorophyll}$ content index in resistant plants, $\# \mathrm{CC}-\mathrm{MR}-\mathrm{MS}=\mathrm{Chlorophyll}$ content index in moderately resistant to moderately susceptible plants, @CC-S= Chlorophyll content index in susceptible plants. 
Table 2. Comparison of chlorophyll content index in different maturity groups through paired ' $t$ ' test.

\begin{tabular}{lccc}
\hline Group I & t Stat & Group II & t Stat \\
\hline CCI R-CCI MR-MS & $0.0495^{\text {ns }}$ & CCI R-CCI MR-MS & $0.114^{\mathrm{ns}}$ \\
CCI R-CCI S & $3.499^{\mathrm{s}}$ & CCI R-CCI S & $7.847^{\mathrm{s}}$ \\
CCI MR-MS-CCI S & $4.626^{\mathrm{s}}$ & CCI MR-MS-CCI S & $6.600^{\mathrm{s}}$ \\
Group III & & Group IV & \\
CCI R-CCI MR-MS & $0.520^{\mathrm{ns}}$ & CCI R-CCI MR-MS & $0.021^{\mathrm{ns}}$ \\
CCI R-CCI S & $9.750^{\mathrm{s}}$ & CCI R-CCI S & $4.955^{\mathrm{s}}$ \\
CCI MR-MS-CCI S & $7.848^{\mathrm{s}}$ & CCI MR-MS-CCI S & $5.828^{\mathrm{s}}$ \\
\hline
\end{tabular}

$\mathrm{S}$ - Significant when $\mathrm{t}$ stat value is more than $\mathrm{t}$ critical two tail value; ns- Non significant.

Table 3. Correlation coefficient and regression analysis between chlorophyll content index and rust response in susceptible lines in four maturity groups.

\begin{tabular}{lcc}
\hline Group & $\begin{array}{c}\text { Correlation } \\
\text { coefficient (r) }\end{array}$ & Regression F value \\
\hline Group I & $-0.59 * * *$ & $18.63^{* * *}$ \\
Group II & $-0.60 * * *$ & $51.66^{* * *}$ \\
Group III & $-0.59 * * *$ & $75.96 * * *$ \\
Group IV & $-0.35^{\mathrm{ns}}$ & $3.45^{* *}$ \\
\hline
\end{tabular}

20.07, 20.17 and 12.84. In the second group chlorophyll index varied from 2.5 to 34.5 with mean value of 18.3 . Out of 186 accessions 31.72 per cent were resistant, 18.28 per cent were MR-MS and 50 per cent were susceptible. The average CCI of resistant, moderately resistant-moderately susceptible and susceptible accessions was $22.37,22.24$ and 14.34 respectively. The medium late group having 298 accessions had mean CCI of 17 ranging from 2 to 31.9 . 32.56 per cent of the lines were found as resistant, 17.80 per cent were showing the response of MR-MS type and rest 49.70 per cent were susceptible to yellow rust. The average CCI of resistant, moderately resistant-moderately susceptible and susceptible accessions was 20.95, 20.48 and 13.21. The fourth group having 57 accessions had average CCI of 16 ranging from 4.0 - 34.9. 36.84 per cent of the lines were resistant, 47.37 per cent of lines were MR-MS type and only 15.79 per cent of lines were susceptible to stripe rust. The average chlorophyll content of resistant, moderately resistant -moderately susceptible and susceptible accessions was $19.51,19.48$ and 11.78 , respectively.

On the basis of paired ' $t$ ' test analysis it was observed that there was no statistical difference for chlorophyll content index between resistant plants and moderately resistant to moderately susceptible plants in all the groups (Table 2). The non-significant loss of chlorophyll between resistant and moderately resistant to moderately susceptible plants gives assurance for use of APR genes where the response is of MR-MS type. In all the groups the susceptible plants showed loss of chlorophyll in comparison with the resistant plants. The reduction in chlorophyll concentration index was 36.02, 35.90,
36.95 and 39.62 per cent in early, medium-early, medium late and late groups respectively (Table 1).

As the loss of chlorophyll between resistant and moderately resistant to moderately susceptible plants was non-significant, provides the assurance for utilization of APR genes in wheat improvement with no loss of chlorophyll. However, plants susceptible to yellow rust showed loss of chlorophyll content up to $40 \%$ in comparison with the resistant plants. McGrath and Penny packer (1990) reported 54\% reduction in chlorophyll content due to stem and /or due leaf rust in wheat. The reduced chlorophyll content due to various diseases has been attributed to number of processes involved during photosynthesis. There is decline in photosynthetic phosphorylation (Arentzen, 1972; Berghaus and Reisener, 1985; Magyarosy et al., 1976; Montalbini and Buchanan, 1974), Hill reaction activity (Mathre, 1968; Spikes and Stout, 1955; Zaitlin and Jagendrof, 1960) and carbon dioxide assimilation. These changes may partially (Magyarosy et al., 1976; Allen, 1942; Mitchell, 1979) or completely (Berghaus and Reisener, 1985; Wynn, $1963)$ result in reduced chlorophyll content. The pathogen Puccinia striiformis $f$. sp. tritici attacks leaves by forming yellow stripes, thereby reducing photosynthetic activity that may ultimately lead to grain shrivelling. Depending upon the disease severity and varietal differences, Chen (2005) reported 10 to $70 \%$ losses in wheat production due to stripe rust. Early and precise detection of the disease is needed to circumvent such losses.

Since only susceptible plants showed significant chlorophyll loss these were further analysed for correlation and regression analysis. The correlation analysis of disease severity with chlorophyll content index showed the negative association between them. The correlation coefficients were $-0.59,-0.6,-0.59$ and -0.35 in group I, group II, group III and group IV, respectively. The correlation between CCI and disease response was highly significant in all maturity groups except the late maturity group. This might be due to the reason that data were recorded on flag leaves which are more resistant at higher temperature (Line and Chen, 1995). The susceptible genotypes in each group were subjected to regression analysis that showed significant dependence of chlorophyll content on disease severity on all the four maturity groups. Regression analysis showed that the regression 


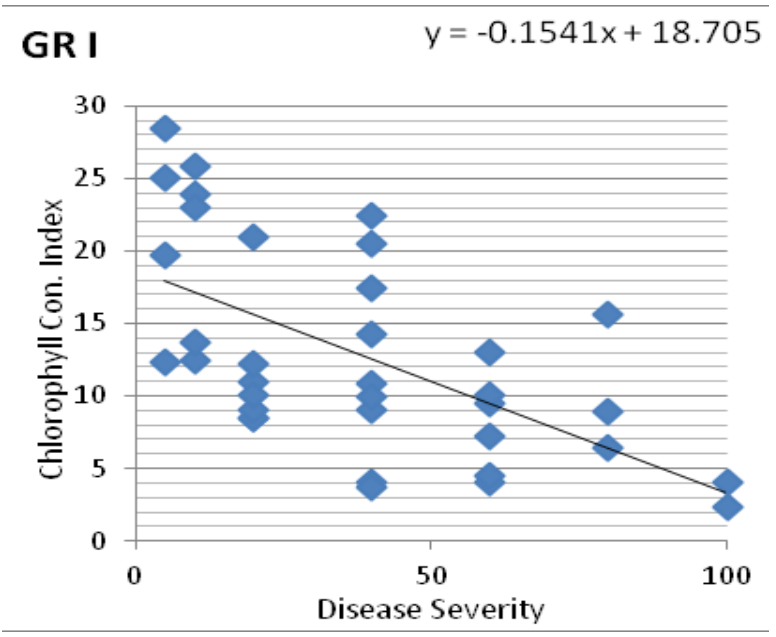

Gr III

$y=-0.1669 x+19.394$

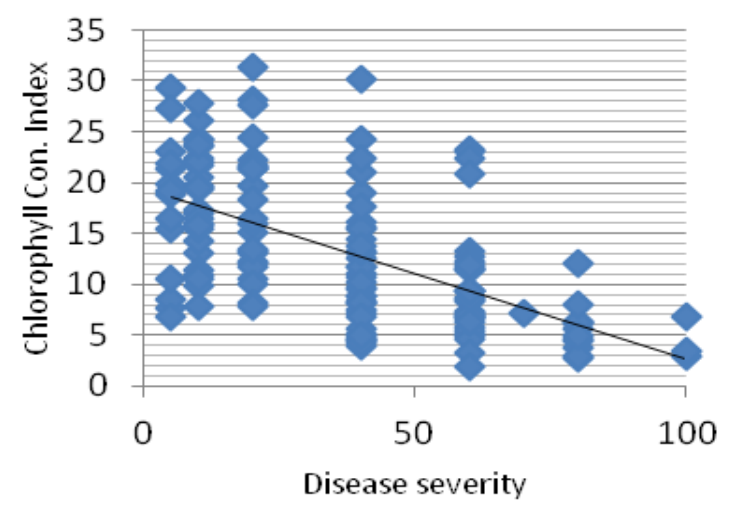

Gr II

$y=-0.1817 x+20.692$

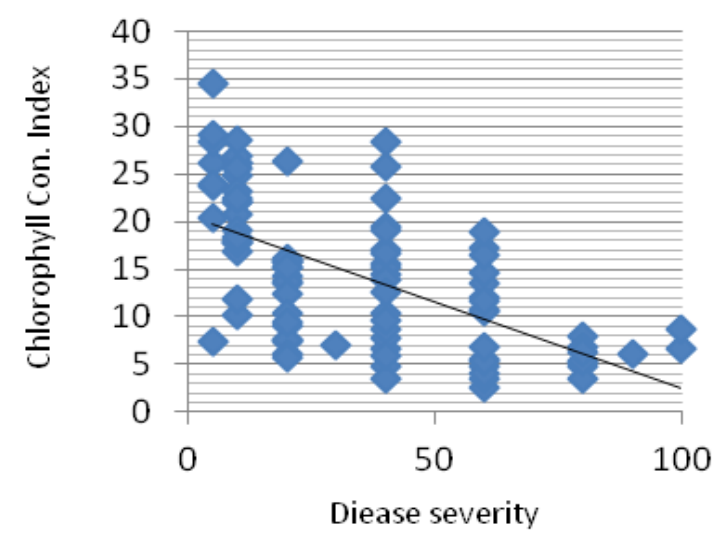

GrIV

$y=-0.056 x+13.862$

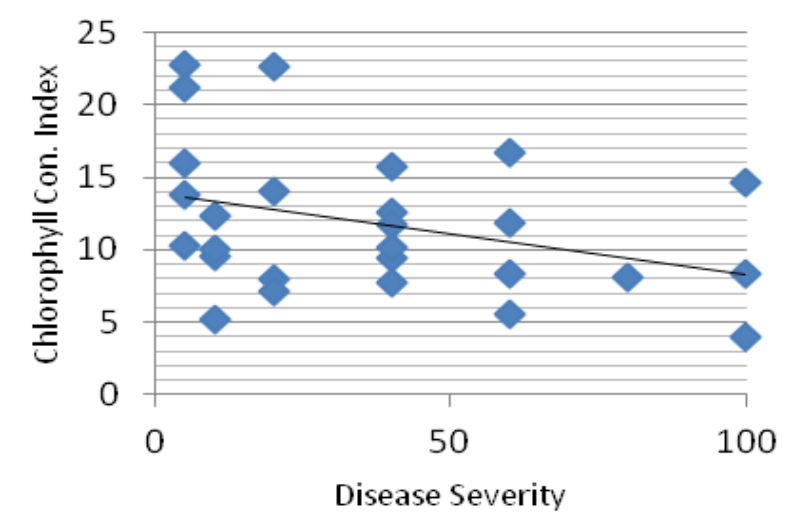

Fig. 1: Regression analysis between chlorophyll content index and disease severity due to stripe rust pathogen in wheat.

of disease severity on chlorophyll index was significant in all the groups (Table 3 ). As there was progress towards higher magnitude of susceptibility linear trend for chlorophyll reduction was observed. There existed a negative relationship between chlorophyll content index and disease severity (Fig.1). The regression equation for each group is presented along with the graphs.

In susceptible accessions, with increasing disease severity of yellow rust a linear trend in chlorophyll reduction was observed. Huang et al. (2005) reported that when winter wheat was infected with yellow rust, there was decrease in leaf chlorophyll content. It showed good relationship between SPAD (Sod-Plant Analysis Development) chlorophyll meter value from and measured chlorophyll concentration. Spitters et al. (1990) observed accelerated leaf and ear senescence in winter wheat genotypes due to leaf rust. Stripe rust is one of the most damaging diseases in wheat worldwide. Various studies have reported relations between spectral reflectance and rust infection (Moshou et al., 2004; Huang et al., 2007, 2012; Devadas et al., 2009; Zhang et al., 2011). An early disease detection system can aid in decreasing losses caused by plant diseases and can further prevent the spread of diseases (Sankaran et al., 2010) by timely control measures.

\section{Conclusion}

The results concluded that huge diversity existed for stripe rust resistance for prevalent races in the indigenous wheat collections and it should be utilized in the breeding programme. However care must be taken to differentiate between the loss of chlorophyll due to stripe rust and other factors. Application of remote sensing reflectance methods can aid in proper understanding of this mechanism. With the progress of disease severity a linear trend for chlorophyll reduction was observed in the susceptible accessions. No difference for chlorophyll content index between resistant and moderately resistant to moderately susceptible plants further supports the use of APR genes for stripe rust resistance in wheat improvement.

\section{REFERENCES}

Allen, P.J. (1942). Changes in the metabolism of wheat leaves induced by infection with powdery mildew. $\mathrm{Am}$. J. Bot., 29: 425-435.

Anonymous, (2014). Progress report of All India Coordinated Wheat \& Barlry Improvement Project 2013-14, Project Director's report. Ed: Indu Sharma, Directorate of Wheat Research, Karnal, India. pp 120.

Arentzen, C.J. (1972). Inhibition of photophosphorylation by 
tentoxin, a cyclic tetrapeptide. Biochim. Biophys. Acta., 283: 539-542.

Berghaus, R. and Reisener, H.J. (1985). Changes in photosynthesis of wheat plants infected with wheat stem rust (Puccinia graminis f.sp. tritici). Phyotopathol Z, 112: 165-172.

Biber, P.D. (2007). Evaluating a Chlorophyll Content Meter on Three Coastal Wetland Plant Species. J. Agril Food Environ Sci, 24: 1-15.

Chen, X.M. (2005). Epidemiology and control of stripe rust (Puccinia striiformis f.sp. tritici) on wheat. Can J Plant Pathol, 27: 314-337.

Devadas, R., Lamb, D.W., Simpfendorfer, S. and Backhouse, D. (2009). Evaluating ten spectral vegetation indices for identifying rust infection in individual wheat leaves. Precision Agric 10: 459-470.

Gomez, K.A. and Gomez, A.A. (1984). Statistical Procedures for Agricultural Research, 2nd ed. John Wiley, New York.

Goodman, R.N., Kiraly, Z. and Wood, K.R. (1986). Photosynthesis. In: The Biochemistry and Physiology of Plant disease. University of Missouri Press, Columbia. pp 46-74.

Herrera-Foessel, S.A., Lagudah, E.S., Huerta-Espino, J., Hayden, M., Bariana, H.S., Singh, D. and Singh, R.P. (2011). New slow rusting leaf rust and stripe rust resistance genes Lr67 and Yr46 are pleiotropic or closely linked. Theor. Appl. Genet., 122: 239-249.

Huang, W., Huang, M., Liangyun, L., Jihua, W., Chunjiang, Z. and Jindi, W. (2005). Inversion of the severity of winter wheat yellow rust using proper hyper spectral index. Transactions of the CSAE, 21(4): 97-103.

Huang, L.S., Zhao, J.L., Zhang, D.Y., Yuan, L., Dong, Y.Y. and Zhang, J.C. (2012). Identifying and mapping stripe rust in winter wheat using multi-temporal airborne hyperspectal images. Int J Agric Biol, 14: 697-704.

Huang, W., Lamb, D.W., Niu, Z., Zhang, Y., Liu, L. and Wang, J. (2007). Identification of yellow rust in wheat using in-situ spectral reflectance measurements and airborne hyperspectral imaging. Precision Agric, 8: 187-197.

Line, R.F. and Chen, X.M. (1995). Success in breeding for and managing durable resistance to wheat rusts. Plant Dis., 79: 1254-1255.

Magyarosy, A.C., Schurmann, P. and Buchanan, B.B. (1976). Effect of powdery mildew infection on photosynthesis by leaves and chloroplasts of sugarbeets. Plant Physiol., 57: 486-489.

Moshoua, D., Bravo, C., West, J., Wahlen, S., McCartney, A. and Ramona, H. (2004). Automatic detection of 'yellow rust in wheat using reflectance measurements and neural networks. Comput Electron Agr, 44: 173-188.

Mathre, D.E. (1968). Photosynthetic activities of cotton plant infected with Verticillium albo-atrum. Phytopath, 58: 137-141.
McGrath, M.T. and Pennypacker, S.P. (1990). Alteration of physiological process in wheat flag leaves caused by stem and leaf rust. Phtyopath, 80: 677-686.

McIntosh, R.A., Dubcovsky, J., Rogers, J., Morris, C., Appels, R. and Xia, X. (2010). Catalogue of gene symbols for wheat: 2010 supplement. http://www.shigen.nig.ac.jp/ wheat/komugi/genes/macgene/supplement2010.pdf.

Mitchell, D.T. (1979). Carbon dioxide exchange by infected first leaf tissue susceptible to wheat stem rust. Trans. $\mathrm{Br}$ Mycol. Soc., 72: 63-68.

Montalbini, P. and Buchanan, B.B. (1974). Effect of rust infection on photophosphoryaltion by isolated chloroplasts. Physiol. Plant. Pathol., 4: 191-196.

Peterson, R.F., Champbell, A.B. and Hannah, A.E. (1948). A diagrammatic scale for estimating rust intensity of leaves and stem of cereals. Peterson RF C26:496-500.

Roelfs, A.P., Singh, R.P. and Saari, E.E. (1992). Rust diseases of wheat: concept and methods of disease management. CIMMYT, Mexico.

Sankaran, S., Mishra, A., Ehsani, R. and Davis, C. (2010). A review of advanced techniques for detecting plant diseases. Comput Electron Agr, 72: 1-13.

Singh, R.P., Huerta-Espino, J., Bhavani, S., Herrera-Foessel, S.A., Singh, D., Singh, P.K., Velu, G., Mason, R.E., Jin, Y., Njau, P. and Crossa, J. (2011). Race non-specific resistance to rust diseases in CIMMYT wheats. Euphytica, 179: 175-186.

Singh, R.P., William, H.M., Huerta-Espino, J. and Rosewarne, G. (2004). Wheat rust in Asia: meeting the challenges with old and new technologies. In: New directions for a diverse planet. Proceedings of the 4 th international crop science congress, 26 September -1-October 2004, Brisbane, Australia.

Spikes, J.D. and Stout, M. (1955). Photochemical activity of chloroplasts isolated from sugarbeet infected with virus yellows. Science, 122: 375-376.

Spitters, C.J.T., Van Roermund, H.J.W., Van Nassau, H.G.M.G., Schepers, J. and Mesdag, J. (1990). Genetic variation in partial resistance to leaf rust in winter wheat: disease progress, foliage senescence and yield reduction. Netherlands J Plant Path, 96(1): 3-15.

Wynn, W.K. (1963). Photosynthetic phosphorylation by chloroplasts isolated from rust infected oats. Phytopath, 53: 1376-1377.

Zaitlin, M. and Jagendrof, A.T. (1960). Photosynthetic phosphorylation and Hill reaction activities of chloroplasts isolated from plants infected with tobacco mosaic virus. Virology, 12: 477-486.

Zhang, J., Huang, W., Li, J., Yang, G., Luo, J., Gu, X. and Wang, J. (2011). Development, evaluation and application of a spectral knowledge base to detect yellow rust in winter wheat. Precision Agric, 12: 716-731. 